\title{
Possible association between ABCC8 C49620T polymorphism and type 2 diabetes in a Nigerian population
}

\author{
Godwill Azeh Engwa ${ }^{1,7^{*}}$, Friday Nweke Nwalo ${ }^{2}$, Claribel Chidimma Chikezie ${ }^{3}$, Christie Oby Onyia ${ }^{3}$,
} Opeolu Oyejide Ojo ${ }^{4,5}$, Wilfred Fon Mbacham ${ }^{6}$ and Benjamin Ewa Ubi ${ }^{7}$

\begin{abstract}
Background: The association between ABCC8 gene C49620T polymorphism and type 2 diabetes (T2D) in populations of diverse ethnic backgrounds has been reported. However, such occurrence in an African population is yet to be established. This case-control study involving 73 T2D and 75 non-diabetic (ND) patients investigated the occurrence of this polymorphism among T2D patients in Nigeria and assessed its relationship with body lipids of patients.

Methods: Demographic and clinical characteristics of patients were collected and lipid profile indices including total cholesterol (TC), triglyceride (TG), low density lipoprotein (LDL) and high density lipoprotein $(\mathrm{HDL})$ were assayed. Restriction fragment length polymorphism-PCR (RFLP-PCR) was employed to genotype the ABCC8-C49620T polymorphism using Pstl restriction enzyme.
\end{abstract}

Results: This study revealed significantly $(p<0.05)$ higher prevalence of the T allele of the ABCC8 gene in T2D patients (33.1\%) compared to ND patients (28.0\%). The mutant $\Pi$ genotype was also higher than the CC and CT genotypes in T2D patients compared to ND patients but did not show any significant risk $(p>0.05)$ of T2D for the unadjusted codominant, dominant and recessive models. Following age adjustment, the mutant genotypes (CT and $T$ ) showed significant $(p<0.05)$ risk of T2D for all the models with the recessive model presenting the greatest risk of T2D (OR: 2.39, 95\% Cl: 1.16-4.91, $p<0.018)$. The TT genotype significantly $(p<0.05)$ associated with high level of HDL and reduced levels of TC, TG and LDL in non-diabetic patients but was not associated with any of the demographic and clinical characteristics among T2D patients.

Conclusions: ABCC8 C49620T polymorphism showed possible association with T2D marked by predominance of the mutant TT genotype in T2D patients. However, the relationship between $\Pi$ genotype and lipid abnormalities for possible beneficial effect on people suffering from T2D is unclear.

Keywords: Type 2 diabetes, ABCC8 gene, Genotyping, C49620T variant, Nigeria

\section{Background}

Diabetes, one of the leading non-communicable diseases (NCD), has been recognized as an important cause of premature death and disability globally [1]. According to WHO, the global prevalence of the disease has risen from 108 million in the 1980 s to a current figure of 422 million

\footnotetext{
*Correspondence: engwagodwill@gmail.com; gengwa@gouni.edu.ng ${ }^{1}$ Biochemistry, Department of Chemical Sciences, Godfrey Okoye University, P.M.B 01014, Thinkers Corner, Enugu, Nigeria

${ }^{7}$ Department of Biotechnology, Ebonyi State University, P.M.B. 53, Abakaliki, Nigeria

Full list of author information is available at the end of the article
}

[2]. This increasing prevalence is becoming more prominent in middle or low income countries and T2D accounts for about $90 \%$ of all cases of diabetes [1].

T2D is a complex metabolic disease involving defective carbohydrates and lipids metabolism. This disease is characterized by high level of blood glucose due to impaired secretion of insulin and/or insulin resistance [3]. The principal role of insulin is to promote glucose uptake from blood or intercellular spaces into skeletal muscle cells and adipocytes or for transportation to other cells where glucose is needed [4]. Normally,

(c) The Author(s). 2018 Open Access This article is distributed under the terms of the Creative Commons Attribution 4.0 International License (http://creativecommons.org/licenses/by/4.0/), which permits unrestricted use, distribution, and reproduction in any medium, provided you give appropriate credit to the original author(s) and the source, provide a link to the Creative Commons license, and indicate if changes were made. The Creative Commons Public Domain Dedication waiver (http://creativecommons.org/publicdomain/zero/1.0/) applies to the data made available in this article, unless otherwise stated. 
pancreatic $\beta$-cells constantly synthesize insulin irrespective of the levels of blood glucose. Insulin, stored within vacuoles of $\beta$-cells is only secreted in response to elevated blood glucose levels. The secretion of insulin is controlled by the ATP-sensitive potassium $\left(\mathrm{K}_{\mathrm{ATP}}\right)$ channel. This channel consists of four pore forming subunits of Kir6.2 along with four sulfonylurea receptor (SUR) subunits [5]. SUR1 is the site where sulfonylurea proteins bind to trigger insulin secretion and it is coded by the ATP binding cassette, subfamily $C$, member 8 (ABCC8) gene.

The ABCC8 gene was identified as the locus for familial persistent hyperinsulinaemic hypoglycaemia of infancy, an autosomal recessive disorder characterized by unregulated insulin secretion [6]. Polymorphisms in the $A B C C 8$ gene has been associated with insulin response in Mexican American subjects [7] and T2D in French Canadians [8], but not in a Scandinavian cohort [9]. The C49620T variant of the ABCC8 gene is the most common polymorphism found to be associated with T2D [10]. Though association between $\mathrm{C} / \mathrm{T}$ polymorphism of $A B C C 8$ gene on exon16-3 (rs1799854) has been shown to be associated with T2D in many populations groups [11], this association in people from African ethnic background living with T2D has not been established. Therefore, this study investigated the association of C49620T polymorphism of the ABCC8 gene with T2D and body lipids in a Nigerian population.

\section{Methods}

\section{Study population and design}

This study is part of a case-control study that recruited T2D patients and patients without diabetes (ND) who are 30 years old or above visiting Enugu State University Teaching Hospital (ESUTH), Enugu Nigeria. Patients considered as T2D patients were diagnosed according the IDF criteria [12] with at least 1 year history of diabetes. Nondiabetic control patients were those without T2D or hyperglycaemia. Participants included in the study were without any critical health condition or complications of diabetes and were not on hospital admission. Women who are breastfeeding or pregnant as well as HIV positive patients were excluded from the study. The sample size (n) was calculated according to Charan and Biswas [13] using the formula: $n=\frac{2 \mathrm{SD}^{2}\left(\mathrm{Za} / 2+\mathrm{Z}_{\mathrm{B}}\right)^{2}}{\mathrm{~d}^{2}}=74.19$.

Where; $\mathrm{SD}=$ standard deviation, $\mathrm{Z}_{\mathrm{a} / 2}=\mathrm{Zscore}$ for type 1 error of $5 \%, Z_{B}=Z$ score at $95 \%$ power and $d=$ Effect size from previous study [14]. Thus, 74 participants were recruited for each arms (case and controls) making a total of 148 participants.

\section{Ethical considerations}

The study was conducted in accordance with the Helsinki Declaration. Before the commencement of study, ethical clearance was obtained from ESUTH ethics committee (Approval No: ESUTHP/C-MAC/RA/034/174). Written informed consent was obtained from all patients before participation in the study.

\section{Data collection and biochemical analyses}

Following recruitment, participants were administered a research questionnaire which sought relevant demographic information including age, sex, ethnicity, location and disease history. Systolic blood pressure (SBP) and diastolic blood pressure (DBP) were measured using an automatic sphygmomanometer. In addition, anthropometric parameters including body weight, height and waist circumference (WC) of participants were measured. Weight and height of participants were used for the estimation of Body Mass index (BMI) as weight $(\mathrm{Kg}) /$ height $^{2}\left(\mathrm{~m}^{2}\right)$.

Fasting blood glucose (FBG) was measured from whole blood using an Accucheck glucometer [15]. Total cholesterol (TC), low density lipoprotein (LDL), triglyceride (TG) and high-density lipoprotein (HDL) were measured in serum using commercially available kits (Randox Laboratories Ltd., United Kingdom) following the manufacturer's recommended protocol. TC was determined according to the enzymatic method of Allain and collaborators [16], TG was determined by the enzymatic method of Esders and Michira [17] and HDL by the precipitation method of Grove [18]. LDL was estimated using the Freidwald's formula: $\mathrm{LDL}=\mathrm{TC}-(\mathrm{TG} / 5)-\mathrm{HDL}$ [19].

\section{Molecular genotyping of $A B C C 8$ C49620T variant}

DNA was extracted using the GeneJET Genomic DNA Purification kit (K0721) by Thermo Fisher Scientific Inc., USA following the manufacturer's recommended procedure. The ABCC8 C49620T (rs1799854) gene was amplified in a PCR reaction as previously reported by $\mathrm{He}$ et al. [20], using primers with the following sequences; Forward - 5'-TTGGGTGCATCTGTCTGTCTGTCTTT-3' and Reverse: 5'-AGCCCACCTGCCCCACGAT-3'. The PCR mix contained $8 \mu \mathrm{l}$ of genomic DNA (< $10 \mathrm{ng}), 12 \mu \mathrm{l}$ of taq quick-load $2 \times$ master mix (New England Biolab (NEB) , USA) and $4 \mu \mathrm{l}$ of $50 \mu \mathrm{M}$ of each primer. The PCR condition includes an initial denaturation at $94{ }^{\circ} \mathrm{C}$ for $5 \mathrm{~min}$ followed by 35 cycles of denaturation at $94{ }^{\circ} \mathrm{C}$ for $20 \mathrm{~s}$, annealing at $62{ }^{\circ} \mathrm{C}$ for 40 s and extension at $72{ }^{\circ} \mathrm{C}$ for $40 \mathrm{~s}$ with the final extension at $72{ }^{\circ} \mathrm{C}$ for $8 \mathrm{~min}$. The $122 \mathrm{bp}$ amplicon of $A B C C 8$ was visualised on $2 \%$ agarose gel (100 V for $20 \mathrm{~min})$. Restriction digestion was achieved using $10 \mathrm{U}$ PstI restriction enzyme (1ul, New England Biolabs, USA) for $6 \mathrm{~h}$ at $37^{\circ} \mathrm{C}$. Restriction fragments were resolved on a $3 \%$ agarose gel stained with ethidium bromide and visualized under UV light. The C49620 allele was cleaved into 88 and $34 \mathrm{bp}$ restriction fragments, but T49620 allele remains uncleaved (122 bp). 


\section{Statistical analysis}

Data was analyzed using Statistical Package for Social Sciences (SPSS) version 16. Anthropometric, FBG and lipid profile data were expressed as frequencies or mean \pm Standard Error of the Mean (S.E.M). Parametric independent sample $t$-test was used to compare mean differences of the lipid profile data and baseline study parameters for the various $\mathrm{ABCC} 8 \mathrm{C} / \mathrm{T}$ genotypes of participants. Pearson chi-square $\left(\chi^{2}\right)$ test was used to test for the HardyWeinberg equilibrium by comparing genotype and allele frequencies in the diabetic and non-diabetic subjects. Binary and multinomial logistic regression were used to determine the odd ratio (OR) by comparing allele and genotype frequencies between diabetic and non-diabetic patients. A confidence interval of $95 \%$ was taken and a $p$-value less than 0.05 was considered statistically significant.

\section{Results}

In total, $73 \mathrm{~T} 2 \mathrm{D}$ patients and $75 \mathrm{ND}$ patients were recruited for the study. The demographic and clinical characteristics of the study population are summarized in our previous publication [21]. As summarized in Table 1, all 148 samples were successfully amplified for ABCC8 C49620T gene fragment with molecular size of $122 \mathrm{bp}$ (Fig. 1a). Following restriction digestion, the expected product sizes were DNA fragment of 88 and 34 bp for normal homozygote CC genotype, fragments with 122 and 88 bp for a heterozygote CT genotype and an uncleaved band with size $122 \mathrm{bp}$ for the mutant homozygote TT genotype (See Fig. 1b). The 34 bp was not seen on the gel. The mutant $\mathrm{T}$ allele was significantly $(p<0.05)$ predominant in both the ND and T2D patients than the wild C allele. Moreover, the prevalence of the $\mathrm{T}$ allele was greater in the T2D patients (33.1\%) compared with their ND counterparts (28.0\%). The homozygote CC and heterozygote CT genotypes were more prevalent in ND patients compared with T2D patients while the homozygote mutant TT genotype showed greater prevalence in T2D patients compared to ND patients. The CT genotype was not associated with T2D risk $(p>0.05)$ while the TT genotype was associated with risk of T2D (OR: 2.58, 95\% CI: 1.15-5. $77, p<0.0021)$ when compared with the CC genotype after adjusting age. The distribution of the genotype frequencies between T2D patients and ND patients did not violate the Hardy-Weinberg equilibrium $\left(\chi^{2}=2.78 ; p=0.249\right)$.

To determine the model that predicts the greatest risk (OR) of T2D, the codominant, dominant and recessive models were evaluated as shown in Table 2. The codominant model (CC vs. CT vs. TT) showed no significant risk of T2D (OR: $0.56(0.27-1.17, p=0.311)$ with the CT and TT genotypes compared along with $\mathrm{CC}$ genotype. The dominant model $(\mathrm{CC}$ vs. $\mathrm{CT}+\mathrm{TT}=\mathrm{XT})$ with the $\mathrm{T}$ allele carriers (XT genotype) did not shown any significant risk of T2D when compared with the CC genotype (OR: $1.60,95 \%$ CI: $0.79-3.23, p=0.191$ ). Similarly, the recessive model $(\mathrm{CX}=\mathrm{CC}+\mathrm{CT}$ vs. $\mathrm{TT})$ did not show any significant risk of T2D when the TT genotype was compared to the CX genotype (OR: 1.73, 95\% CI: 0.90-3.33, $p=0.098$ ). However, following age adjustment, the mutant genotypes (CT and TT) showed significant risk $(p<0.05)$ of T2D for all the models; the codominant, dominant and recessive models with the recessive model presenting the greatest risk (OR: 2.39, 95\% CI: 1.16-4.91, $p=0.018)$ as shown in Table 2.

The relationship of $\mathrm{ABCC} 8(\mathrm{C} / \mathrm{T})$ polymorphism with demographic and clinical characteristics of participants is summarized in Table 3. Comparison of ABCC8 C/T genotypes $(\mathrm{CC}, \mathrm{CT}, \mathrm{TT})$ did not show any significant differences $(p>0.05)$ on the anthropometric parameters (BMI and WC) of patients. The levels of FBG and lipid profile parameters (TC, TG and LDL) were not significantly different $(p>0.05)$ among the various genotypes (CC, CT and TT) in the study population. However, HDL was significantly higher in patients with the mutant homozygote TT genotype $(p=0.005)$. To confirm the above finding, the relationship between $\mathrm{ABCC} 8(\mathrm{C} / \mathrm{T})$ polymorphism with demographic and clinical characteristics was further assessed separately among T2D

Table 1 Association of ABCC8 C/T alleles and genotypes in participants

\begin{tabular}{|c|c|c|c|c|c|}
\hline & $\mathrm{ABCC} 8 \mathrm{C} / \mathrm{T}$ variant & T2D (\%) patients & ND (\%) patients & OR $(95 \% \mathrm{Cl})$ & $p$-value \\
\hline \multirow[t]{3}{*}{ Allele } & C & $48(16.2)$ & $67(22.6)$ & - & \\
\hline & $\mathrm{T}$ & $98(33.1)$ & $83(28.0)$ & $1.7(1.06-2.73)$ & 0.028 \\
\hline & Total (2 N) & $146(49.3)$ & $150(50.7)$ & & \\
\hline \multirow[t]{4}{*}{ Genotype } & $\mathrm{CC}$ & 19 (12.8) & $27(18.2)$ & - & \\
\hline & $C T$ & $10(6.8)$ & $13(8.8)$ & $\begin{array}{l}1.09(0.39-3.01) \\
1.26(0.44-3.60)^{a}\end{array}$ & $\begin{array}{l}0.863 \\
0.668^{\mathrm{a}}\end{array}$ \\
\hline & $\pi$ & $44(29.7)$ & 35 (23.6) & $\begin{array}{l}1.79(0.86-3.73) \\
2.58(1.15-5.77)^{a}\end{array}$ & $\begin{array}{l}0.122 \\
0.021^{\mathrm{a}}\end{array}$ \\
\hline & Total (N) & $73(49.3)$ & $75(50.7)$ & & \\
\hline
\end{tabular}

The results showed significant differences $(p<0.05)$ in allelic and genotypic frequencies between the T2D and ND patients after adjusting for age $O R$ odd ratio $\mathrm{OR}, \mathrm{Cl}$ confidence interval, $\mathrm{N}$ number of participants

${ }^{\mathrm{a}}$ Indicates age adjustments of study participants 


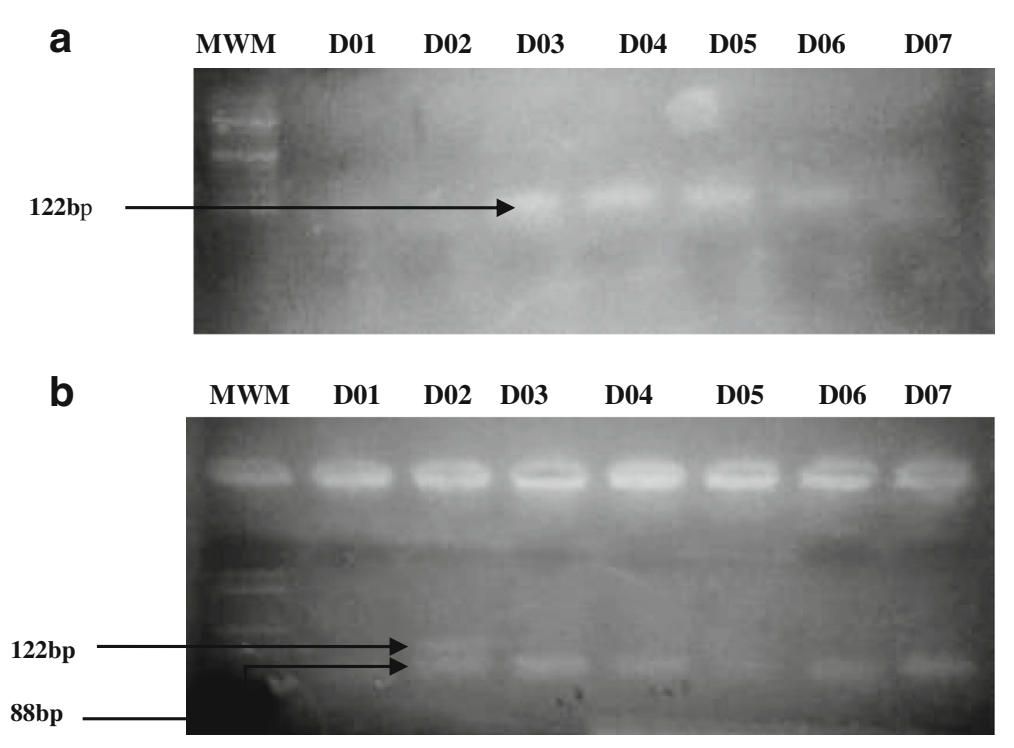

Fig. 1 RFLP-PCR of ABCC8 C49620T Polymorphism. a shows the presence of the amplified gene for D01-D07 at 122 bp. b shows the restriction digest products of the gene. A 122 bp indicates the T allele while a 88 bp indicates the C allele. Sample D01 and D03-D07 show the presence of the wild-type homozygote CC genotype while D02 shows the presence of the heterozygote CT genotype. MWM indicates 100 bp molecular weight marker

patients as well as ND patients as summarized in Table 4. Among non-diabetic patients, TC, TG and LDL levels were significantly lower $(p<0.05)$ while HDL was significantly higher $(p<0.005)$ in patients with the mutant TT genotype compared to the CT and TT genotypes. On the other hand, there were no significant differences $(p>0.05)$ of demographic and clinical characteristics for the various genotypes $(\mathrm{CC}$, $\mathrm{CT}$ and TT) among type 2 diabetes patients.

\section{Discussion}

Insulin resistance, insulin secretion and obesity are the most prevalent underlying causes of T2D and thus, much interest has been to identify potential related genes involved and possible mutations that may confer susceptibility to the disease. Polymorphisms of the $\mathrm{ABCC} 8$ gene which encodes SUR1, a surface receptor for sulfonylurea that regulates insulin secretion, has been investigated with much concern on the C49620T variant which has shown to be associated with T2D [22]. Our study showed predominance of the T allele over the $\mathrm{C}$ allele with a significant risk $(p<0.05)$ of T2D. This is in contrast to findings from other regions across the globe where the wild type $C$ allele is usually predominant in the population [23, 24]. The homozygote mutant TT genotype was more frequent than the homozygote wild type CC genotype while the heterozygote CT was the least frequent. The TT genotype was more frequent in T2D patients compared with their ND counterparts and

Table 2 Association of ABCC8 C/T genotypes in participants based on risk models

\begin{tabular}{|c|c|c|c|c|c|}
\hline & ABCC8 C/T genotypes & T2D (\%) patients & ND (\%) patients & OR $(95 \% \mathrm{Cl})$ & $p$-value \\
\hline \multirow[t]{2}{*}{ Codominant model } & $\mathrm{CC}$ & 19 (12.8) & $27(18.2)$ & - & \\
\hline & CT & $10(6.8)$ & $13(8.8)$ & - & \\
\hline (CC vs. CT vs. TT) & $\pi$ & $44(29.7)$ & $35(23.6)$ & $\begin{array}{l}0.56(0.27-1.17) \\
1.04(1.01-1.07)^{\mathrm{a}}\end{array}$ & $\begin{array}{l}0.311 \\
0.009^{\mathrm{a}}\end{array}$ \\
\hline Dominant model (TX) & $C C$ & 19 (12.8) & $27(18.2)$ & - & \\
\hline (CC vs. $C T+\Pi=X T)$ & $\Pi+\mathrm{CT}$ & $54(36.5)$ & $48(32.4)$ & $\begin{array}{l}1.60(0.79-3.23) \\
2.13(1.00-4.52)^{a}\end{array}$ & $\begin{array}{l}0.191 \\
0.05^{a}\end{array}$ \\
\hline Recessive model (CX) & $\mathrm{CC}+\mathrm{CT}$ & $29(19.6)$ & $40(27.0)$ & - & \\
\hline \multirow[t]{2}{*}{$(C X=C C+C T$ vs. $T)$} & $\pi$ & $44(29.7)$ & 35 (23.6) & $\begin{array}{l}1.73(0.90-3.33) \\
2.39(1.16-4.91)^{\mathrm{a}}\end{array}$ & $\begin{array}{l}0.098 \\
0.018^{\mathrm{a}}\end{array}$ \\
\hline & Total (N) & $73(49.3)$ & $75(50.7)$ & & \\
\hline
\end{tabular}

The results showed significant differences $(p<0.05)$ in genotype frequencies between the T2D and ND patients after adjusting for age for all models $O R$ odd ratio $\mathrm{OR}, \mathrm{Cl}$ confidence interval, vs. versus, $N$ number of participants

andicates age adjustments of study participants 
Table 3 Relationship of ABCC8 (C/T) polymorphism with demographic and clinical characteristics of participants

\begin{tabular}{lllll}
\hline & CC genotype & CT genotype & T genotype & $p$-value \\
\hline Age $($ year $)$ & $55.98 \pm 2.16$ & $53.57 \pm 2.56$ & $50.84 \pm 1.62$ & 0.148 \\
WC $(\mathrm{cm})$ & $94.19 \pm 2.66$ & $97.00 \pm 4.02$ & $94.75 \pm 1.99$ & 0.836 \\
BMl $\left(\mathrm{Kg} / \mathrm{m}^{2}\right)$ & $29.24 \pm 1.51$ & $28.73 \pm 1.25$ & $30.05 \pm 1.15$ & 0.818 \\
FBG $(\mathrm{mg} / \mathrm{dl})$ & $119.69 \pm 15.59$ & $97.43 \pm 12.28$ & $118.92 \pm 9.36$ & 0.545 \\
TC $(\mathrm{mg} / \mathrm{dl})$ & $185.46 \pm 20.52$ & $217.42 \pm 19.75$ & $247.78 \pm 25.75$ & 0.206 \\
TG $(\mathrm{mg} / \mathrm{dl})$ & $192.12 \pm 11.49$ & $220.36 \pm 18.23$ & $187.64 \pm 15.09$ & 0.470 \\
LDL $(\mathrm{mg} / \mathrm{dl})$ & $118.61 \pm 20.64$ & $132.02 \pm 20.71$ & $161.90 \pm 26.39$ & 0.460 \\
HDL $(\mathrm{mg} / \mathrm{dl})$ & $36.11 \pm 2.47$ & $41.88 \pm 3.98$ & $57.38 \pm 5.23$ & 0.005 \\
\hline
\end{tabular}

Results showed a significantly higher $(p<0.05) \mathrm{HDL}-\mathrm{c}$ level in patients with $\mathrm{T}$ genotype. Results are expressed as mean \pm S.E.M

S.E.M standard error of the mean, WC waist circumference, $B M I$ body mass index, FBG fasting blood glucose, $T C$ total cholesterol, $T G$ triglyceride, $L D L$ low density lipoprotein, $H D L$ high density lipoprotein

vice versa for the $\mathrm{CC}$ genotype. When the mutant genotypes (TT, TT + CT) were compared with the CC genotype between T2D patients and ND patients, there was no significant risk $(p<0.05)$ of T2D for the dominant, codominant and recessive models. However, when these models were adjusted for age, the risk of the mutant genotype to cause T2D was significant $(p<0.05)$. This result suggests that the mutant genotypes TT and CT have possible risk of predisposing people to T2D. This finding is consistent with previous reports on the association between $\mathrm{ABCC} 8 \mathrm{C} / \mathrm{T}$ polymorphism and T2D $[25,26]$ as well as the association between this polymorphism and gestational diabetes [27] together with the attendant effects on insulin secretion $[7$, 8]. However, this study is in contrast to a large-scale association studies which showed no association of the polymorphism with T2D [28]. The recessive model predicted the greatest risk for T2D and suggests that the mutant TT genotype is the most vulnerable genotype with a greaterrisk of T2D than the CT and CC genotypes. The distribution of genotypes between T2D patients and ND patients did not violate the Hardy-Weinberg equilibrium in this study $(\mathrm{X} 2=2.781 ; p=0.249)$, thus the population under consideration was stable.

Since insulin has diverse functions in the body regulating carbohydrates and lipids by stimulating lipid synthesis from glucose and prevents lipid degradation or lipolysis [29], we evaluated the relationship between the ABCC8 C/T polymorphism with obesity, cholesterol, triglyceride and lipoproteins. Findings from our study showed no significant differences $(p>0.05)$ of these genotypes (CC, CT and TT) with anthropometric or obesity parameters (BMI, WC), FBG and serum lipids (TC, TG and LDL) in the study population. This confirms findings of previous studies which also showed no association of this polymorphism with anthropometric parameters [23], obesity and body fat [22]. However, HDL level was significantly higher $(p<0.05)$ in patients with the TT genotype compared to those with $\mathrm{CT}$ and $\mathrm{CC}$ genotypes in the study population. Further comparison of the clinical and demographic characteristics on the various genotypes (CC, CT and TT) among nondiabetic patients, showed TC, TG, LDL to be significantly lower $(p<0.05)$ while HDL was significantly higher $(p<0.05)$ in patients with the mutant TT genotype. If similar finding is observed for T2D patients, it may suggest that the TT genotype may improve the HDL level as well as reduce TC, TG and LDL levels in patients, thereby improving lipid abnormalities which may be beneficial to T2D as HDL is known to play essential role in the removal of free cholesterol from blood thereby reducing T2D susceptibility [30]. However, no significant differences $(p>0.05)$ were observed for the demographic and clinical characteristics among type 2 diabetes patients. Thus, it is not yet conclusive to propose that TT genotype may improve the diabetic status of patients by reducing lipid abnormalities as such finding was not observed among type 2 diabetes patients

Table 4 Comparison of ABCC8 (C/T) polymorphism with demographic and clinical characteristics among T2D and ND patients

\begin{tabular}{|c|c|c|c|c|c|c|c|c|}
\hline & \multicolumn{4}{|c|}{ Type 2 Diabetes patients } & \multicolumn{4}{|c|}{ Non-Diabetic patients } \\
\hline & CC genotype & $\mathrm{CT}$ genotype & TT genotype & $p$-value & CC genotype & CT genotype & TT genotype & $p$-value \\
\hline Age (year) & $58.67 \pm 2.37$ & $61.50 \pm 2.59$ & $55.05 \pm 1.55$ & 0.128 & $54.19 \pm 3.22$ & $47.46 \pm 3.19$ & $45.53 \pm 2.89$ & 0.111 \\
\hline$W C(\mathrm{~cm})$ & $103.12 \pm 2.89$ & $104.00 \pm 2.50$ & $98.32 \pm 2.37$ & 0.342 & $88.12 \pm 3.56$ & $90.70 \pm 6.86$ & $89.94 \pm 3.26$ & 0.608 \\
\hline $\mathrm{BMI}\left(\mathrm{Kg} / \mathrm{m}^{2}\right)$ & $32.74 \pm 3.09$ & $29.31 \pm 1.86$ & $31.29 \pm 1.83$ & 0.764 & $26.82 \pm 1.25$ & $28.25 \pm 1.76$ & $28.46 \pm 1.16$ & 0.909 \\
\hline $\mathrm{FBG}(\mathrm{mg} / \mathrm{dl})$ & $203.99 \pm 27.91$ & $150.30 \pm 13.73$ & $153.19 \pm 13.35$ & 0.128 & $60.37 \pm 3.18$ & $56.77 \pm 7.96$ & $73.94 \pm 7.26$ & 0.146 \\
\hline $\mathrm{TC}(\mathrm{mg} / \mathrm{dl})$ & $259.88 \pm 43.84$ & $235.58 \pm 10.16$ & $318.20 \pm 43.86$ & 0.516 & $135.84 \pm 10.65$ & $203.46 \pm 34.17$ & $161.27 \pm 5.29$ & 0.010 \\
\hline $\mathrm{TG}(\mathrm{mg} / \mathrm{dl})$ & $224.97 \pm 15.33$ & $286.25 \pm 19.69$ & $237.82 \pm 23.97$ & 0.482 & $170.22 \pm 14.96$ & $169.68 \pm 19.01$ & $124.55 \pm 7.51$ & 0.010 \\
\hline $\mathrm{LDL}(\mathrm{mg} / \mathrm{dl})$ & $183.44 \pm 46.36$ & $141.22 \pm 11.43$ & $241.07 \pm 44.22$ & 0.445 & $75.39 \pm 9.25$ & $124.93 \pm 36.14$ & $64.64 \pm 6.64$ & 0.010 \\
\hline $\mathrm{HDL}(\mathrm{mg} / \mathrm{dl})$ & $31.12 \pm 4.36$ & $38.31 \pm 7.02$ & $33.46 \pm 2.62$ & 0.612 & $39.43 \pm 2.81$ & $44.63 \pm 4.66$ & $87.45 \pm 9.11$ & $<0.0001$ \\
\hline
\end{tabular}

Results showed a significantly $(p<0.05)$ lower TC, TG, LDLand higher HDL levels in non-diabetic patients with $\pi$ genotype. Results are expressed as mean \pm S.E.M

S.E.M standard error of the mean, WC waist circumference, $B M I$ body mass index, FBG Fasting blood glucose, $T C$ total cholesterol, $T G$ triglyceride, $L D L$ low density lipoprotein cholesterol, HDL high density lipoprotein cholesterol 
in this study. Further detailed studies are needed to better explain or confirm the association of ABCC8 C/T polymorphic genotypes with T2D as well as body lipids taking into consideration that the sample size of this study may be limiting to make generalized conclusions.

\section{Conclusion}

This study revealed possible association of ABCC8 C49620T polymorphism with T2D marked by predominance of the mutant $\mathrm{T}$ allele and TT genotype in T2D patients. However, the relationship between TT genotype and lipid abnormalities for possible beneficial effect on people suffering from T2D is not clear. Thus, further studies are needed to further investigate this possibility.

\section{Abbreviations \\ ABCC8: ATP binding cassette, subfamily C, member 8; BMI: Body Mass index; bp: Base pair; Cl: Confidence interval; ESUTH: Enugu State University Teaching Hospital; HDL: High density lipoprotein; HIV: Human immunodeficiency virus; KATP: ATP-sensitive potassium channel; LDL: Low density lipoprotein; ND: Non-diabetic; OR: Odd ratio; RFLP-PCR: Restriction fragment length - Polymerase Chain Reaction; S.E.M: Standard error of the mean; SPSS: Statistical Package for Social Science; SUR: Sulfonylurea receptor; T2D: Type 2 diabetes; TC: Total cholesterol; TG: Triglyceride; UD: Undigested sample; WC: Waist circumference; WHO: World Health Organisation}

\section{Acknowledgements}

The authors are thankful to the medical students of ESUTH Enugu for their assistance in data and blood collection. Also, we are grateful to Mrs. Ngozika Mariagoretti Ukwueze of the Biotechnology laboratory, Godfrey Okoye University, Enugu Nigeria for her assistance throughout the study.

\section{Funding}

This study was partly supported by the competitive research grant of Godfrey Okoye University, Enugu Nigeria.

\section{Availability of data and materials}

The datasets used and/or analysed during the current study are available from the corresponding author on reasonable request.

\section{Authors' contributions}

GAE conceived and designed the study along with FNN and BEU. GAE carried out the field work and laboratory work along with CCC and COO while OOO, WFM and GAE were involved in data analysis and interpretation. WFM, OOO, FNN, BEU and GAE were all involved in drafting the manuscript. All authors read and approved the final manuscript.

\section{Ethics approval and consent to participate}

The study design was reviewed and approved by the ethical committee of ESUTH Enugu, Nigeria with approval no: ESUTHP/C-MAC/RA/034/174. Written informed consent was obtained from all patients willing to participant in the study.

\section{Competing interests}

The authors declare that they have no competing interests.

\section{Publisher's Note}

Springer Nature remains neutral with regard to jurisdictional claims in published maps and institutional affiliations.

\section{Author details}

'Biochemistry, Department of Chemical Sciences, Godfrey Okoye University, P.M.B 01014, Thinkers Corner, Enugu, Nigeria. ${ }^{2}$ Department of Biotechnology, Federal University, Ndufu-Alike Ikwo (FUNAI), P.M.B. 1010, Abakaliki, Nigeria. ${ }^{3}$ Department of Biotechnology, Godfrey Okoye University, P.M.B 01014 , Thinkers Corner, Enugu, Nigeria. ${ }^{4}$ Department of Biology, Chemistry and
Forensic Science, School of Sciences, University of Wolverhampton, Wolverhampton WV1 1LY, UK. ${ }^{5}$ Bioscience Research Education and Advisory Centre, Ibadan, Nigeria. ${ }^{6}$ Laboratory for Public Health Research Biotechnologies, The Biotechnology Centre, University of Yaounde I, BP 8094 Yaounde, Cameroon. ${ }^{7}$ Department of Biotechnology, Ebonyi State University, P.M.B. 53, Abakaliki, Nigeria.

Received: 2 February 2018 Accepted: 1 May 2018

Published online: 12 May 2018

\section{References}

1. IDF. IDF Diabetes Atlas. Brussels: Sixth Edition International Diabetes Federation; 2013. http://www.diabetesatlas.org/.

2. WHO. Global report on diabetes. Geneva: WHO Press, World Health Organization; 2016. http://www.who.int/diabetes/global-report/en/.

3. Das SK, Elbein SC. The genetic basis of type 2 diabetes. Cell science. 2:100-31.

4. Stumvoll M, Goldstein BJ, van Haeften TW. Type 2 diabetes: principles of pathogenesis and therapy. Lancet. 2005;365:1333-46.

5. Aguilar-Bryan $\mathrm{L}$, et al. Cloning of the beta cell high-affinity sulfonylurea receptor: a regulator of insulin secretion. Science. 1995;268(5209):423-6.

6. Thomas PM, Cote GJ, Wohllk N, Haddad B, Mathew PM, Rabl W, Aguilar-Bryan $L$, Gagel RF, Bryan J. Mutations in the sulfonylurea receptor gene in familial persistent hyperinsulinemic hypoglycemia of infancy. Science. 1995;268:426-9.

7. Goksel DL, Fischbach K, Duggirala R, Mitchell BD, Aguilar-Bryan L, Blangero J, Stern MP, O'Connell P. Variant in sulfonylurea receptor-1 gene is associated with high insulin concentrations in non-diabetic Mexican Americans: SUR-1 gene variant and hyperinsulinemia. Hum Genet. 1998;103:280-5.

8. Reis AF, Ye WZ, Dubois-Laforgue D, Bellanne-Chantelot C, Timsit J, Velho G. Association of a variant in exon 31 of the sulfonylurea receptor 1 (SUR1) gene with type 2 diabetes mellitus in French Caucasians. Hum Genet. 2000; 107:138-44

9. Altshuler D, Hirschhorn JN, Klannemark M, Lindgren CM, Vohl MC, Nemesh J, Lane CR, Schaffner SF, Bolk S, Brewer C, et al. The common PPARgamma Pro12Ala polymorphism is associated with decreased risk of type 2 diabetes. Nat Genet. 2000;26:76-80.

10. Stefanski A, Majkowska L, Ciechanowicz A, et al. The common C49620T polymorphism in the sulfonylurea receptor gene (ABCC8), pancreatic beta cell function and long-term diabetic complications in obese patients with long-lasting type 2 diabetes mellitus. Exp Clin Endocrinol Diabetes. 2007; 115(5):317-21.

11. Florez JC, Jablonski KA, Kahn SE, Franks PW, Dabelea D, Hamman RF, Knowler WC, Nathan DM, Altshuler D. Type 2 diabetes-associated missense polymorphisms KCNJ11 E23K and ABCC8 A1369S influence progression to diabetes and response to interventions in the diabetes prevention program. Diabetes. 2007;56(2):531-6.

12. WHO-IDF. Definition and diagnosis of diabetes mellitus and intermediate hyperglycemia: report of a WHO/IDF consultation. 2014. Available at: http://www.who.int/diabetes/publications/diagnosis_diabetes2006/en/. Accessed: 1 Oct 2014

13. Charan J, Biswas T. How to calculate sample size for different study designs in medical research? Indian J Psychol Med. 2013;35:121-6.

14. Chen S, Lansdown AJ, Moat SJ, Ellis R, Goringe A, Dunstan FDJ, et al. An observational study of the effect of metformin on B12 status and peripheral neuropathy. Br J Diabetes Vascular Dis. 2012;12:189-93.

15. Trinder P. Determination of blood glucose using 4-aminophenazone as oxygen acceptor. J Clin Pathol. 1969;22(246):1-6.

16. Allain CC, Poon LS, Chan CS, Richmond W. Total cholesterol assay. Clin Chem. 1974;20:470-1.

17. Esders TN, Michira CA. Triglyceride estimation. J Biol Chem. 1997;254:2710-2.

18. Grove TH. Grove's method of high density lipiptotein estimation. Clin Chem. 1979;25:560-2.

19. Friedwald WT, Levy RI, Fredrickson DS. Estimation of the concentration of low-density lipoprotein cholesterol in plasma without use of preparative Ultracenrifugation. Clin Chem. 1972;18:499-502.

20. He Y, Zhang R, Shao X, Hu C, Wang C, Lu J, Bao Y, Jla W, Xiang K. Association of $K C N J 11$ and $A B C C 8$ genetic polymorphisms with response to repaglinide in Chinese diabetic patients. Acta Pharmacol Sin. 2008;29(8):983-9.

21. Engwa AG, Nwalo FN, Obi CE, Onyia C, Ojo OO, Mbacham WF, Ubi BE. Predominance of the a allele but no association of the KCNJ11 rs5219 E23K polymorphism with type 2 diabetes in a Nigerian population. Gen Mol Res. 2018;17(1):gmr16039889. 
22. Laukkanen O, Pihlajamaki J, Lindstrom J, Eriksson J, Valle T, Hamalainen H, et al. Polymorphisms of the SUR1 (ABCC8) and Kir6.2 (KCNJ11) genes predict the conversion from impaired glucose tolerance to type 2 diabetes. The Finnish diabetes prevention study. J Clin Endocrinol Metab. 2004;89:6286-90.

23. Pietrzak-Nowacka M, Safranow K, Bińczak-Kuleta A, Rózański J, Ciechanowski K, Ciechanowicz A. Association of C49620T ABCC8 polymorphism with anthropometric and metabolic parameters in patients with autosomal dominant polycystic kidney disease: a preliminary study. Nefrologia. 2012;32(2):153-9.

24. Moleda P, Binczak-Kuleta A, Homa K, Safranow K, Celewicz Z, Syrenicz A, Stefanski A, Fronczyk A, Majkowska L. The common C49620T polymorphism in the sulfonylurea receptor gene SUR1 (ABCC8) in patients with gestational diabetes and subsequent glucose metabolism abnormalities. Exp Diabetes Res. 2012;2012:1-7.

25. Yokoi N, Kanamori M, Horikawa Y, Takeda J, Sanke T, Furuta H, et al. Association studies of variants in the genes involved in pancreatic beta-cell function in type 2 diabetes in Japanese subjects. Diabetes. 2006;55:2379-86.

26. Hart $L M$, De Knijff $P$, Dekker JM, et al. Variants in the sulphonylurea receptor gene: association of the exon 16- 3t variant with type II diabetes mellitus in Dutch Caucasians. Diabetologia. 1999;42(5):617-20.

27. Rissanen J, Markkanen A, Karkkainen P, et al. Sulfonylurea receptor I gene variants are associated with gestational diabetes and type 2 diabetes but not with altered secretion of insulin. Diabetes Care. 2000;23(1):70-3.

28. Gloyn AL, Weedon MN, Owen KR, Turner MJ, Knight BA, Hitman G, et al. Largescale association studies of variants in genes encoding the pancreatic beta-cell KATP channel subunits Kir6.2 (KCNJ11) and SUR1 (ABCC8) confirm that the KCNJ11 E23K variant is associated with type 2 diabetes. Diabetes. 2003;52:568-72

29. Jin W, et al. Lipases and HDL metabolism. Trends Endocrinol Metab. 2002; 13(4):174-8.

30. Bitzur R, Cohen H, Kamari Y, Shaish A, Harats D. Diabetes Care. 2009;32(2): S373-7.

\section{Ready to submit your research? Choose BMC and benefit from:}

- fast, convenient online submission

- thorough peer review by experienced researchers in your field

- rapid publication on acceptance

- support for research data, including large and complex data types

- gold Open Access which fosters wider collaboration and increased citations

- maximum visibility for your research: over $100 \mathrm{M}$ website views per year

At BMC, research is always in progress.

Learn more biomedcentral.com/submissions 